\title{
IMPROVING STUDENTS' LEARNING WITH A MOBILE AUGMENTED REALITY APPROACH - THE EDUPARK GAME
}

\author{
Lúcia Pombo \\ Research Centre on Didactics and Technology in the Education of Trainers (CIDTFF) \\ Department of Education and Psychology, University of Aveiro, 3810-193 Aveiro, Portugal \\ Margarida M. Marques \\ Research Centre on Didactics and Technology in the Education of Trainers (CIDTFF) \\ Department of Education and Psychology, University of Aveiro, 3810-193 Aveiro, Portugal
}

\begin{abstract}
Mobile devices are intensively used by the Portuguese youth in their daily life, but not in school activities. Despite this gap, research shows that technology can promote students' learning. This paper comprises a survey study where mobile learning is analyzed through the eyes of 244 students attending the $2^{\text {nd }}$ or $3^{\text {rd }}$ Cycles of Basic Education (CBE). The acknowledged advantages and difficulties of the use of mobile devices for learning, as well as the educational value and usability of a specific mobile learning strategy, using the EduPARK app and game, were analyzed. Results revealed that most students owned a mobile device and were able to use them to learn. They had a positive perspective regarding mobile learning and valued the advantages of being easy to find up-to-date information, motivating for learning and easy to carry along. Difficulties are related to the use of mobile devices to learn, such as requiring an internet connection, its slowness, and prohibition of mobile devices in schools. The EduPARK game achieved an average Educational Value Scale of 83.8 and an average System Usability Scale of 80.2, indicating its high educational value and usability for students. This paper presents empirical evidence regarding the effectiveness of the integration of mobile game-based AR approaches in Basic Education to promote students' learning. It also includes an example of excellent cros-subjects educational materials that comprises a very useful tool for teachers and students to explore scientific knowledge by accessing appealing information on biological and historical references of a local urban park.
\end{abstract}

\section{KEYWORDS}

Mobile Learning, Augmented Reality, Outdoor Activities, Game-Based Learning, Authentic Learning, Basic Education

\section{INTRODUCTION}

Mobile devices, such as cell phones and smartphones, are being intensively used by the Portuguese youth in their daily life; however, these devices are seldom used in school activities (Simões et al., 2014), as they are still perceived as disruptors of learning and their use is frequently forbidden during instructional time (Liu et $a l .$, 2014). The gap between the use of mobile devices inside and outside schools can lead to students' disengagement with learning activities, thus, impacting negatively their academic success (Reyes et al., 2012).

Research has shown that mobile learning can promote student learning in non-high education contexts, with few published studies with neutral or negative results (Liu et al., 2014; Chee et al., 2017; Crompton, Burke and Gregory, 2017). Frequently, the literature reported student gains of increased attention, motivation, and development of key competencies, as well as improved classroom climate (Martí \& Mon, 2018; Sung et al., 2016). Mobile science learning, with a behaviorist approach to learning, in formal educational contexts, particularly in elementary schools, seem to have been the focus of the educational research community (Chee et al., 2017; Liu et al., 2014).

The EduPARK (http://edupark.web.ua.pt/) is a research and development project with the aim to generate and implement original, attractive and cross-subjects teaching strategies. The project employed a design- 
based research approach to create an interactive application with augmented reality (RA) for Android devices, with a set of educational learning games and integrating geocaching principles (Pombo et al., 2017b; Pombo \& Marques, 2018). The final version of the EduPARK app is available in the Google Play Store (edupark.web.ua.pt/app) for Android devices, not requiring internet connection after download.

The app was developed for students and teachers from primary to higher education to be explored in a specific informal outdoor learning context, thus promoting an active, contextual and authentic learning (Herrington \& Parker, 2013). Besides the educational community, local residents and visiting tourists can also use the app in an lifelong learning approach.

One of the EduPARK's innovative aspects relates with the fact that the promoted learning methodology combines a technology that is familiar to students with locations they see as their own. Thus, this methodology moves learning out of the classrooms and into the spaces of the students's community, such as their local urban park - the Infante D. Pedro Park, in Aveiro (Portugal). It is a large green area, with diverse fauna and flora, and even a reasonable sized lake with mallard ducks and amphibian species that deserves to be explored, in order to provide community education valuing conservative modes, to raise awareness about the importance of biodiversity and to promote the need for everyone to adopt more sustainable lifestyles to support healthy ecosystems (Pombo et al., 2017a). This may contribute to associate a type of technological device, which usually is associated to leisure activities, such as listening to music, watch videoclips or social networking, and to high risk of excessive use (Simões et al., 2014), to healthy activities such as walking, nature observation or face-to-face socialization. Moreover, the intensive use of mobile devices and other screen devices is associated with several obesity risk factors (Kenney and Gortmaker, 2017), which highlights the importance of using those devices for learning while exercising in a park.

The purpose of this paper is to present a survey study that analyzes mobile learning through students' opinion regarding the use of mobile devices for learning, including their advantages and difficulties, as well as the educational value of a specific mobile learning strategy, reified in the EduPARK game, after an experience of exploring it in formal and non-formal educational contexts. The educational value was analyzed concerning: (a) learning value; (b) intrinsic motivation; (c) engagement; (d) authentic learning; (e) lifelong learning; and (f) conservation and sustainability habits. Additionally, the app's usability is also studied as it can influence the exploration of the game.

The remaining paper presents: i) a theoretical framework of the study; ii) a contextualization regarding the EduPARK app and game; iii) methodological options; iv) results and discussion in the light of literature; and v) main conclusions, including suggestions of future work.

\section{THEORETICAL FRAMEWORK}

The use of technology to learn is not a new strategy. With the pervasiveness of mobile devices, their use in sustaining learning, either intentionally or not, was unavoidable. So, using, e.g., smartphones or tablets to support social and/or content interactions to learn, across physical locations and educational contexts, has been referred to as mobile learning (Crompton, Burke and Gregory, 2017). Among its affordances are i) the small size and light weight of devices that allow easily carrying them to different places (Sung, Chang and Liu, 2016) and extending learning beyond the traditional classroom environment (Liu et al., 2014); ii) the interactivity with others and with media content (Burden and Maher, 2014); and iii) the panoply of contextual and situated learning activities they can provision, trough the proliferation of diverse hardware and applications (Parsons, 2014). Moreover, mobile learning research has shown that the use of this technology can promote student learning in K-12 educational contexts, with few published studies with neutral or negative results (Liu et al., 2014; Chee et al., 2017; Crompton, Burke and Gregory, 2017). Frequently reported student gains are increased attention, motivation, and development of key competencies, as well as improved classroom climate (Swan et al., 2005; Sung, Chang and Liu, 2016; Martí and Mon, 2018). Though, the literature recognizes as limitations for mobile learning: i) the small screen size; ii) the processing limitations in connectivity and in computing (Liu et al., 2014); as well as iii) the possibility of disruption, cheating, cyberbullying and accessing inappropriate content on the Internet (Pedro et al., 2018). Additionally, mobile learning may entrench digital divides regarding technology access, technological skills and learning competencies (Parsons, 2014) and it requires high preparation from teachers (Sung, Chang and Liu, 2016). 
According to Crompton and colleagues (2017), mobile science learning, with a behaviorist approach to learning in elementary schools and, thus, formal educational contexts, seem to have been the focus of the educational research community so far. Hence, more research is needed regarding authentic, contextualized and cross-subjects learning approaches for mobile learning in outdoor informal learning settings, such as urban parks.

The dissemination of mobile devices has supported the access of the general public to Augmented Reality (AR) technologies. These allow overlapping virtual elements, such as 3D models, with real objects of the physical world, in real-time, producing a new experience (Azuma et al., 2001; Dunleavy and Dede, 2014). Those virtual elements can be triggered by real-world image recognition or by the user's location. AR has potential to increase learning performance, as it can make boring content more enjoyable and can be used to provide immediate feedback and support autonomous learning (Akçayır \& Akçayır, 2017).

The literature has a growing number of studies combining mobile technologies and game-based learning (GBL). This approach refers to the promotion of knowledge and skills acquisition through the use of games (Qian and Clark, 2016) and has the potential to increase learner motivation, self-directedness, and social and inquiry skills (Giannakas et al., 2018), particularly if it activates prior knowledge and offers instant feedback (Ketelhut and Schifter, 2011). Mobile educational games can provide opportunities to meaningfully engage students in learning of relevant educational content (Liu et al., 2014); however, this teaching methodology requires a carefull balance of the play and the learning outcomes (Giannakas et al., 2018) or it is not likely to be effective (Sung, Chang and Liu, 2016). The EduPARK is using geocaching principles to enhance the gameplay experience for the app users, by finding hidden treasures to promote curiosity, a powerful intrinsic motivator.

Both mobile devices and AR technologies can provide authentic learning experiences. These technologies can situate the learner in a realistic physical and social context and scaffold learning processes (Dunleavy and Dede, 2014). Authentic learning builds on constructivist learning theories, particularly on situated learning, and includes features such as providing an authentic learning context and collaborative construction of knowledge (Herrington \& Parker, 2013), giving students an active role in learning as they experience and use information in ways that are grounded in reality, instead on memorizing facts in abstract situations.

Barnes (2015) defines cross-curricular learning as the experience, at a macro level, of using the skills, knowledge and attitudes of a number of different disciplines to address a single experience, problem, question, theme or idea, with the curriculum as focus. Cross-curricular methods have been perceived to have motivating, inclusive, sensitizing, enriching and uniting effects (Faultley and Savage, 2012). Although there is some discussion on the most effective way of cross-curricular learning, it has been pointed that subjects' progression and integrity is best ensured by limiting the subjects involved to two or three (Barnes, 2015).

The preservation of the historical and biological heritage from city parks requires educational values from communities, such as conservation attitudes and sustainable lifestyles (Pereira, Lopes and Pinho, 2006). The use of new interactive technologies may provide an opportunity for students to be physically engaged in task solving (Bacca et al., 2014), experience biodiversity in Nature and value the protection of green spaces. This promotes an active participation of students, constructing their knowledge, as well as the development of values enhancing an authentic learning (Herrington and Parker, 2013).

City parks have the potential to provide learning experiences that not only promote the importance of plants, habitats and their conservation, but also influence the values, attitudes and actions of their visitors. To do this effectively, however, a well-designed understanding of the gain of preserving biological and historical patrimonial for the future well-being of the planet is needed. Indeed, the Council Heads of the Australian Botanic Gardens claims that raising public awareness of the importance of biodiversity is critical in fostering conservation because it leads to the need to preserve natural habitats, and understanding the threats and consequences of losing biodiversity, emphasizing the key role of adopting counteractive measures (Ballantyne, Packer and Hughes, 2008).

These outdoor environments attract students and teachers as well as a wide range of domestic and international tourists and other regular visitors from the local areas (Ballantyne, Packer and Hughes, 2008). The Infante D. Pedro Park is potentially well-placed to offer community education about conservation; it's a large green area, with diverse fauna and flora (with about 70 native and exotic species of trees and bushes and even a lake with reasonable dimensions (Plomp and Nieveen, 2013) that deserves to be explored, in order to provide community education valuing conservative modes, to raise awareness about the importance of biodiversity (Pereira, Lopes and Pinho, 2006) and to promote the need for everyone to adopt more sustainable lifestyles to support healthy ecosystems. 
Skills such as problem solving, digital and communication skills, critical thinking, analytical thinking, creative thinking, collaboration, and teamwork are required by organizations when recruiting job candidates. For students to develop such skills, a more active and authentic learning method is needed (Pombo et al., 2011) where learners take the responsibility for their learning and are engaged participants rather than passive observers (Pombo, Loureiro and Moreira, 2010, 2011).

\section{THE AUGMENTED REALITY EDUPARK PROJECT, APP \& GAME}

EduPARK (http://edupark.web.ua.pt) integrates a multidisciplinary team that involves researchers from the University of Aveiro (Portugal) comprising three areas: Education, Biology and Computer Science. The main relevance is its innovation in terms of outdoor learning strategies, in formal, informal and non-formal contexts, articulating curriculum contents with game challenges and with technology. The partnership with the City Council of Aveiro allowed the installation of 32 plant identification plaques in the Infante D. Pedro Park that give access to AR information developed by the project team.

The project organizes regular activities for students and visitors, as well as teacher training, to collect systematic data to better understand the educational value of mobile learning in outdoor settings. With this strategy, learning moves beyond traditional classroom environments to nature spaces that students can physically explore at the same time they make connections with curricular contents. To date, EduPARK has involved about 900 students from primary to higher education, 200 teachers and lots of tourists.

The EduPARK app (Fig.1) development fits a design-based research methodology with four cycles of development involving user testing and evaluation (Pombo and Marques, 2018). The app was progressively refined according to the users' feedback in each cycle and the stable version of the EduPARK app is now available in the Google Play Store (edupark.web.ua.pt/app) for Android devices, not requiring internet connection after download. The app can be used autonomously, and at any time, promoting authentic learning so that visitors can enjoy a healthy walk while learning. The mobile app was developed using Unity 5 , a popular cross-platform game engine, since Vuforia is currently the most widely adopted platform for AR technology (Unity Technologies, 2017).

The EduPARK app has two main modes: i) explore freely mode, with no specific game or associated trajectory, and ii) game mode that includes cross-subjects educational guides, or quiz games developed for specific audiences, from basic to higher education, but also for tourists/public in general in a lifelong learning perspective. The last one is available both in Portuguese and in English to reach also foreign visitors. The school level guides were developed in articulation with the curriculum directives for specific audience and include subjects as Biology, Maths, History, etc. Therefore, to develop these guides, it was important to carefully analyze the National Curriculum to identify multidisciplinary issues (e.g., integrating Biology and History or Biology and Math) that might be explored in the selected park. The EduPARK app is, thus, a resource with potential impact in schools, local community and tourism sector. An app with educational potential for so diverse target publics and in formal (school visits to the park), non-formal (e.g., in environmental education sessions promoted by the local City Council) or informal learning contexts (e.g., a family visiting the park explores it through one of the EduPARK games) is unique in the literature (Laine, 2018).

The AR markers are: i) in plaques, installed in the park for that purpose (see Fig. 2Fig. 2A); or ii) in tiles (see Fig. 2B), already existing in the park. The AR information overlays on top of a real-time camera feed of a feature within the park, augmenting the reality, and it can include images, audios, videos, schemes, or 3D models, such as 3D plant leaves. The AR integrated in the plaques includes information about plant species, such as leaf, flower, fruit, origin, ecology and curiosities about the species; the AR integrated on tiles is about historical and regional issues with interest for the general public (Fig. 2). For example, pointing the camera into a tile of the Tea House, one can appreciate the original architectural project of the House that is overlaid on the real Tea House or visualize the current use of moliceiro boat, once used to collect moliço (vascular algae).

EduPARK game features integrates a set of aims/principles, as addressed by Pombo, Marques, Afonso, Dias \& Madeira (in press), including: (i) contextualized learning in the park, e.g., related with the botanical species or with the historical monuments in the park; (ii) cross-subjects learning, e.g., using flowers to address issues about symmetry axis; (iii) recommendation to play in small teams, although it is perfectly 
playable individually as well, as generally research suggests that collaboration is more effective than competition for reaching achievements, as the app's educational challenges can promote collaborative discussion of ideas; (iv) the context is successful either in formal (school visits to the park), non-formal (e.g., in environmental education sessions of app use promoted by the local City Council) or informal learning contexts (e.g., a family visiting the park explores it through one of its games/educational guides); (v) userfriendly, so users, even children in primary education, can use it without support of the EduPARK team.

There are a set of features that make the EduPARK game particularly effective in promoting learning. In what concerns pedagogical affordances, the game is grounded in the constructivist theories of authentic and contextualized learning. As such, it takes advantage of the context as facilitator of learning, as it prompts the players to observe several park elements to answer correctly the questions. For instance, the game invites the players to observe their surroundings and identify the musical instrument represented at the top of the park bandstand. It is also a game premise to have the learner assuming an active role in his/her learning process of interacting with the game resources, close environment and other team members. Additionally, as mentioned above, the EduPARK team purposely developed the game to promote cross-subjects learning, so it includes questions that, e.g., prompt the players to interpret the 'not drinking water' signal and answer in English, which is a foreign language for Portuguese children. The game also includes questions that prompt the players to acknowledge and respect the biodiversity, such as the one that suggest listening to the sound of a bird that inhabits the park.
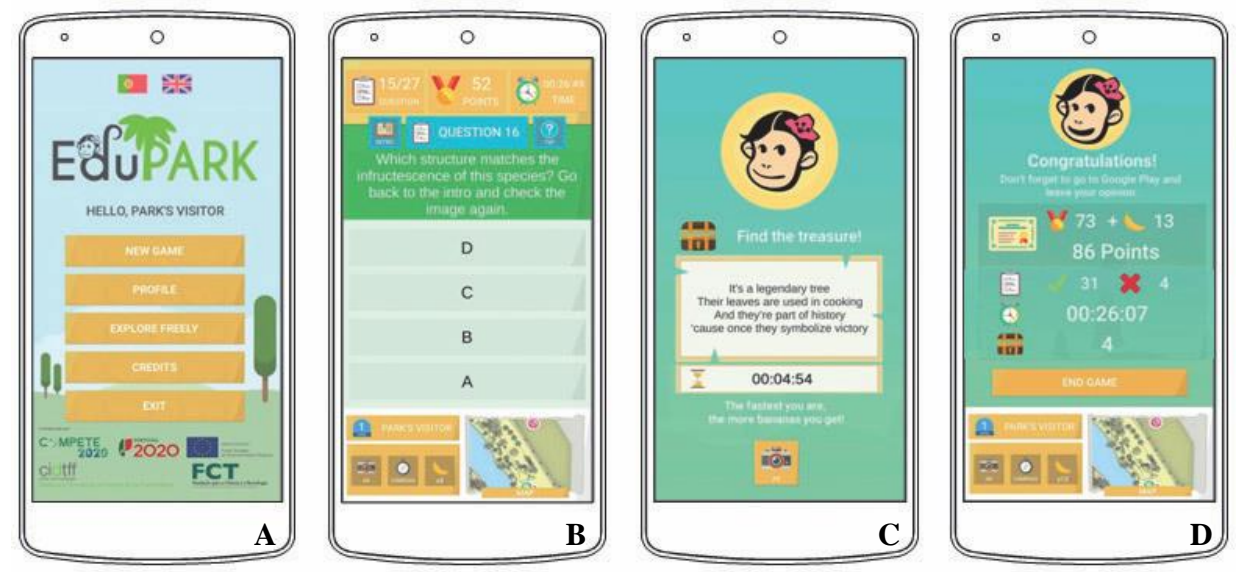

Fig. 1. EduPARK app: A) initial screen with language options (Portuguese or English), profile setting and different modes of app use; B) multiple-choice question; C) treasure hunt challenge; and D) final screen with game results
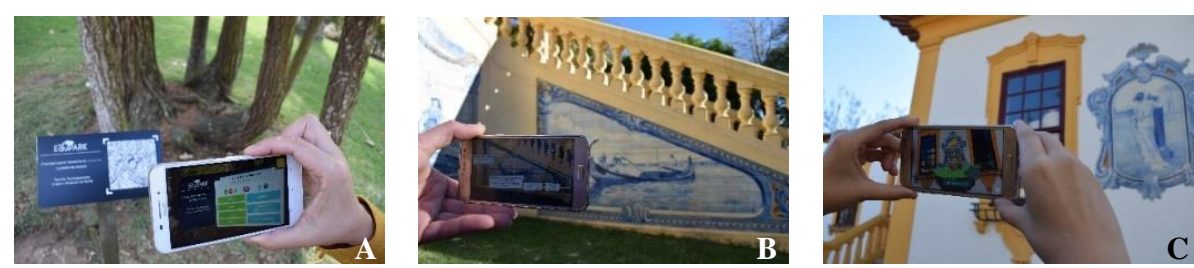

Fig. 2. The EduPARK app triggering AR content: A) about plant species, using identifying plaques with AR image markers; B) about regional issues, using historical tiles as markers; C) virtual treasure displaying on the mobile screen

The EduPARK game also presents gaming affordances, such as a diverse gameplay experience. The players are asked to find specific locations in the park, to analyze the app contents (both AR triggered by plaques and by historical tiles, videos, audios, images or even the park map) and to answer quiz-questions with no time constrains. Additionally, players are also prompting to look for hidden virtual caches or treasures, but with a time limit, thus, sustaining a different game experience. Moreover, the popular treasure hunt (Laine, 2018) reifies the geocaching principles. Players are presented with challenges and riddles that require knowledge about the park (see Fig. 1C) to find a specific virtual chest with bananas (see Fig. 2C), having five minutes to find it. The longer the time players need to find each treasure, the less bananas they collect. Looking for hidden treasures can arouse curiosity, which is an intrinsic motivator and keeps the 
player engaged in learning during the game, hence, curiosity can result in improved learning and performance (Laine, 2018). The accumulated bananas can be used for help with the following quiz-questions.

\section{METHODOLOGY}

The EduPARK project aims to study how playing a game, supported by an interactive mobile AR app in an outdoor context may promote learning and motivation for learning, among other affective gains. The present paper gives continuity to previous works (Pombo et al., in press) and reports a survey focused on the opinion of students attending the $2^{\text {nd }}$ and $3^{\text {rd }} \mathrm{CBE}$ in what concerns the use of mobile devices for learning, including their advantages and difficulties, as well as the EduPARK app educational value and usability.

Empirical data was gathered throughout the first year of app use in 15 outreach activities organized by the project involving schools and other educational entities. Students were organized in teams of three to five members to collaboratively play with the EduPARK app in the Infante D. Pedro Park (Aveiro, Portugal). A total of 244 students attending $2^{\text {nd }}$ and $3^{\text {rd }} \mathrm{CBE}$ participated in groups, both in formal and non-formal educational contexts, played with the app and participated in this study.

Data collection involved a questionnaire survey, automatic app logging mechanisms regarding the score attained, number of correct and incorrect answers, etc. Data were collected anonymously and research ethics principles were respected.

The questionnaire survey was applied right after the game activity. It was similar to the one used in the previous study for primary education children (Pombo and Marques, in press), which comprises four sections, with multi-choice closed questions in a Likert scale (where 1 corresponds to 'strongly disagree' and 5 to 'strongly agree'). One section collected basic demographic data, as age and gender, students' profile as mobile devices users and their opinion on mobile learning advantages and disadvantages. Other section is about the interest regarding the activity of playing the EduPARK game in the park. Another section refers to the Educational Value Scale (EVS), and the last one is based on the System Usability Scale (SUS) (Brooke, 1996; Martins et al., 2015).

The app logging mechanisms were automatically and anonymously collected information from finished games: a) number of questions answered correctly and incorrectly; b) number of hunted geocaching treasures; c) number of bananas collected in the treasures; d) final score, including the points gained through the collected bananas; and f) time of gameplay.

As to data analysis, individual SUS scores and EVS score were computed according to Brooke (1996), with values varying from 0 to 100 . In the present study, SUS scores were interpreted according to Sauro (2011) and to Bangor et al. (2009). The remaining data were analyzed through descriptive statistics. These sets of data were triangulated to provide a more comprehensive knowledge of students' opinion regarding mobile learning. This analysis will be presented in the next section.

\section{RESULTS AND DISCUSSION}

This section starts with a brief characterization of the study's participants, followed by an analysis of the participant students' opinion regarding the use of mobile devices for learning, the educational value of a specific mobile learning strategy, reified in the EduPARK app, and its usability as well.

The 244 students that participated in the study were $2^{\text {nd }}$ and $3^{\text {rd }} \mathrm{CBE}$ children, who played with the support of the EduPARK app in loco, that is, in the Infante D. Pedro Park, under an activity organized by the project during the first year of public implementation. Students' age ranged from 10 to 16 years-old, being $48.4 \%$ of boys and $51.6 \%$ of girls. At the time of the activity, children were attending grade five to nine in the Portuguese Education System: $63.2 \%$ in grade five; $5.4 \%$ in grade six; $2.2 \%$ in grade seven; $27.4 \%$ in grade eight and $1.8 \%$ in grade nine. Grade five and grade eight were considered particularly suitable for learning in an urban park. This tendency can be associated with the National Curriculum for these years, as it prescribes learning related to the environment protection, ecosystems, biodiversity, etc.

Most students (85.8\%) referred owning an Android mobile device, smartphone or tablet, and claimed they use mobile devices to learn either frequently $(18.8 \%)$ or sometimes $(67.8 \%)$. The remaining students $(13.4 \%)$ mentioned they do not use mobile devices to learn at all. Most of children were already quite familiar with 
mobile devices and considered they were able to employ these technologies for learning. These results seem to support the literature that highlights the mobile devices proliferation (Chee, Yahaya, Ibrahim \& Hasan, 2017), especially in what concerns school aged children.

More than two thirds of the participant students were, at least, able to use mobile devices for learning. This is an indicator that they probably have a positive perspective regarding mobile learning, and Graphic 1 shows the agreement with each advantage sentence.

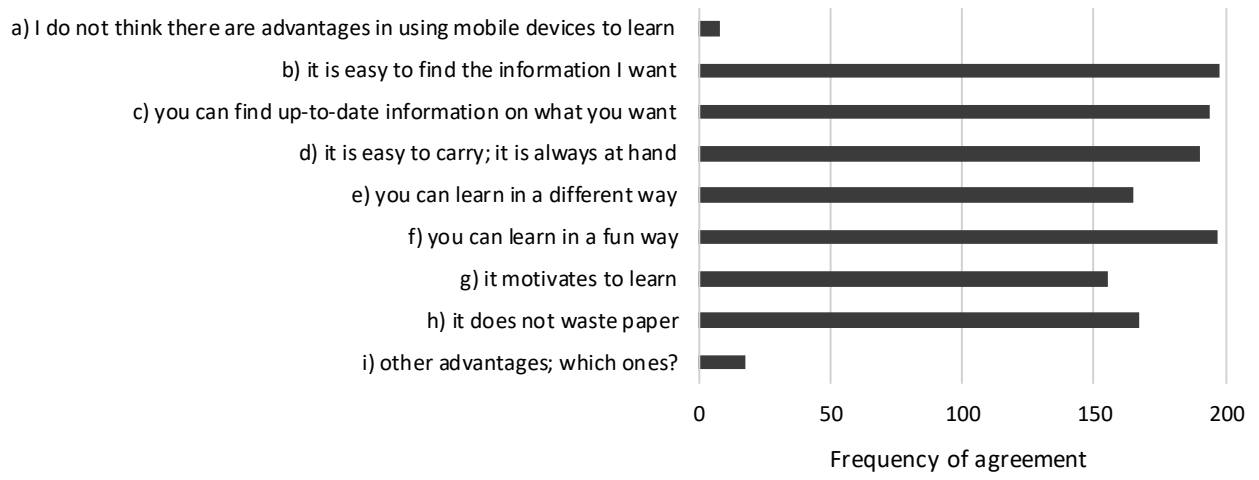

Graphic 1. Students' opinion about advantages in using mobile devices to learn

All sentences achieved a frequency of at least 150 . Only $3.3 \%$ students did not recognize any advantage in mobile learning. Among the most acknowledged advantages are 'it is easy to find the information I want' $(81.1 \%)$, 'you can learn in a fun way' $(80.7 \%)$, and 'you can find up-to-date information on what you want' (79.5\%). Moreover, $7.4 \%$ students added new advantages, such as the shortened time of information search when compared with other methods, not polluting the environment with the printers' tonners, the fun they have when using mobile devices or even not being bored studying with the books.

Regarding the difficulties of mobile learning, Graphic 2 shows that $36.9 \%$ students did not recognize any difficulties in the use of mobile devices to learn. The most mentioned difficulties are the requirement of internet connection $(57.4 \%)$ and its slowness $(41.0 \%)$, and the prohibition of using mobile devices in schools $(41.4 \%)$. The EduPARK project approach contributes to reduce all these constrains, as: i) the game supporting app was conceived for offline use, not requiring internet connection, so its slowness is not an issue; ii) promotes teachers' support in the use of mobile devices to learn; and iii) reduces students' use of other mobile devices software, as they are engaged with the game in the park (Pombo et al., 2017b). Finally, $3.3 \%$ students added new difficulties, such as one cannot always find what one is looking for, not understanding the vocabulary, or even the risk of dropping the mobile device and losing it. Almost all students $(94.3 \%)$ considered the EduPARK activity interesting (27.9\%) or very interesting (66.4\%).

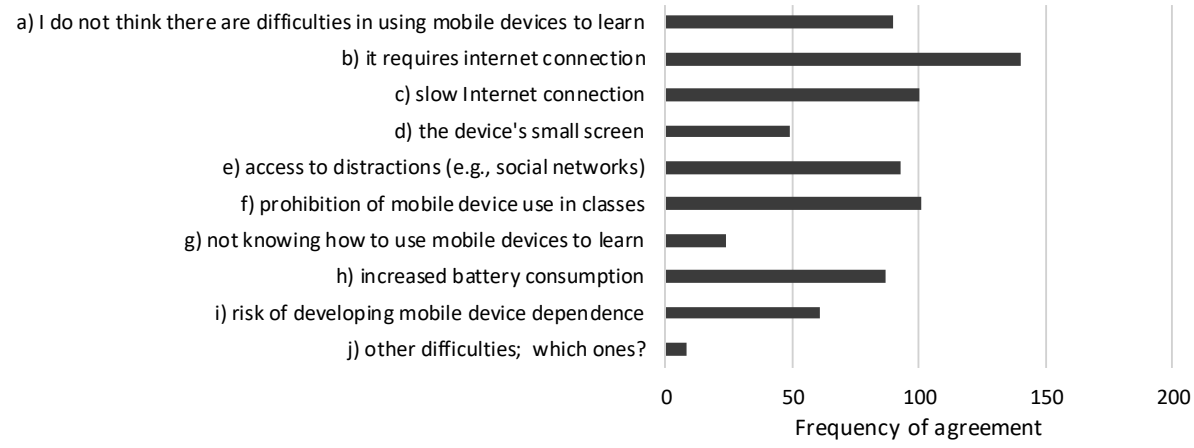

Graphic 2. Students' opinion about difficulties in using mobile devices to learn

Graphic 3 summarizes children's opinion regarding the educational value of the EduPARK game. Their perception was positive, as, e.g., 90.2\% students (strongly) agreed with the statement 'This app shows realworld information that helps you learn' and $86.9 \%$ (strongly) disagreed with the statement 'I do not feel like using this app to learn'. EVS score values ranged from 37.5 to 100 , with an average of 83.8, which seems to 
be a high value, although more studies are needed to sustain that claim. The results seem to reveal that the EduPARK game has educational value for $2^{\text {nd }}$ and $3^{\text {rd }} \mathrm{CBE}$ students.

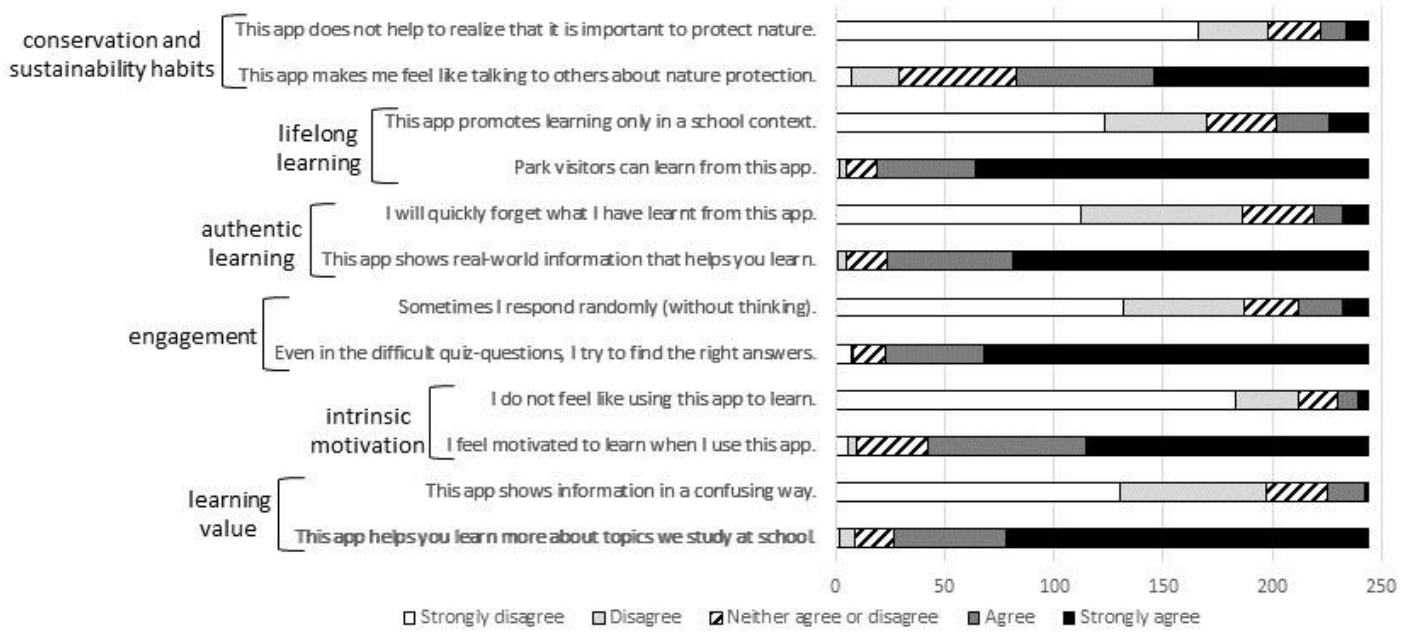

Graphic 3. Second and third CBE students' opinion regarding the educational value of the EduPARK app

Regarding the indicators of learning value, $80.7 \%$ students (strongly) disagreed with the statement 'This app shows information in a confusing way' that assesses negatively the app's learning value. Similarly, opposite results can be found regarding the positive value attribution sentence. Similar results can be found for the remaining indicators. Graphic 4 summarizes children's opinion regarding the usability of the EduPARK app.

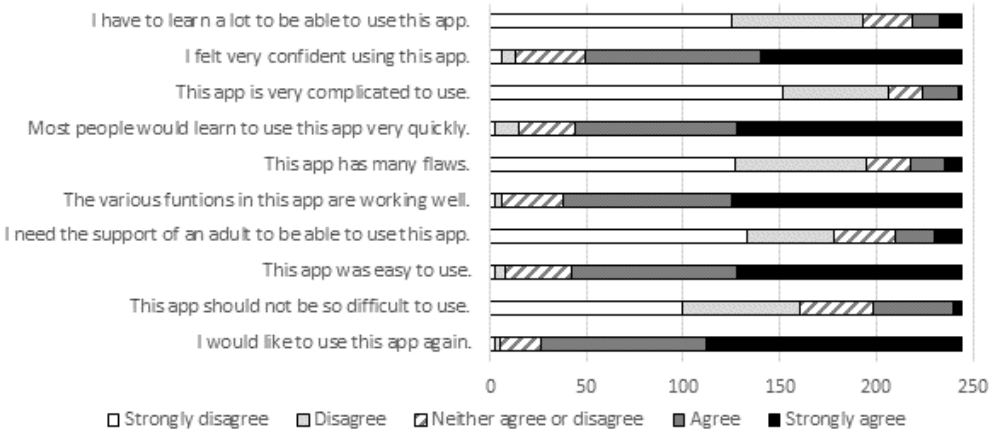

Graphic 4. $2^{\text {nd }}$ and $3^{\text {rd }}$ CBE students' opinion regarding the usability of the EduPARK app

Students' perception was positive, as, e.g., $82.8 \%$ students agreed or strongly agreed with the statement 'This app was easy to use' and $65.6 \%$ disagreed or strongly disagreed with the statement 'This app should not be so difficult to use'. SUS score values ranged from 30.0 to 100 , with an average of 80.2 , which is an higher value than the average SUS value (68) computed by Sauro (2011). Moreover, according to the classification of Bangor et al. (2009), the EduPARK app achieved a good-excellent usability for $2^{\text {nd }}$ and $3^{\text {rd }}$ CBE students.

Students organized in 62 teams, completed the $2^{\text {nd }}$ and $3^{\text {rd }} \mathrm{CBE}$ game during the activities organized by the EduPARK, so the data collected by the app was automatically and anonymously generated from these completed games. These data are presented in Table 1. In 31 quiz-like questions, the students answered correctly an average of 25.5 questions, with a maximum of 31 correct answers and a minimum of 17 . These results reveal that most of the gamers were able to select the right answer of the quiz questions, either because they already knew the answer or because of the adequacy of the app's supporting information. By discovering a maximum of 4 treasures, players can earn a maximum of 20 bananas (five per treasure), according to how quickly they found them. Data reveals that most players found all the treasures and earned an average of 15.2 bananas, so the treasure hunt tasks were quite accessible to most players. The number of earned bananas, of correctly answered questions and of AR contents accessed are all considered to compute the game final score; data revealed that final scores reached an average of 279.9, maximum of 361 and 
minimum of 192. Thus, the results about the children's performance in the game support their views regarding the high educational value of the EduPARK app.

Additionally, the time in game varied from nearly 43 minutes to 1 hour and 55 minutes, with an average of 1 hour and 16 minutes. This factor did not have impact on the players' scores. The gameplay time showed that students were able to stay committed with the game for long periods having a positive performance in the tasks proposed in the app.

Table 1. Automatic app loggings regarding 62 teams who completed the $2^{\text {nd }}$ and $3^{\text {rd }} \mathrm{CBE}$ game

\begin{tabular}{lcccccc}
\hline & $\begin{array}{c}\text { Number of } \\
\text { correct answers } \\
\text { (out of 31) }\end{array}$ & $\begin{array}{c}\text { Number of } \\
\text { incorrect answers } \\
\text { (out of 31) }\end{array}$ & $\begin{array}{c}\text { Number of } \\
\text { treasures } \\
\text { (out of 4) }\end{array}$ & $\begin{array}{c}\text { Bananas } \\
\text { (out of 20) }\end{array}$ & $\begin{array}{c}\text { Final } \\
\text { score }\end{array}$ & $\begin{array}{c}\text { Gameplay } \\
\text { time }\end{array}$ \\
\hline Average & 25.5 & 5.4 & 3.8 & 15.2 & 284.9 & $01: 16: 18$ \\
Maximum & 31 & 14 & 4 & 20 & 361 & $01: 55: 14$ \\
Minimum & 17 & 0 & 2 & 4 & 192 & $00: 43: 39$ \\
\hline
\end{tabular}

\section{CONCLUSION}

The EduPARK project developed an innovative interactive mobile AR game to promote authentic crosssubjects learning in a specific urban park being a resource with potential impact in schools, local community and tourism sector. This work reports the results of the EduPARK app and game implementation with 244 Basic Education students in outdoor activities organized by the project. The focus is students' opinion regarding mobile learning, as well as the educational value and usability of the app and game.

The results point to students' positive perspective regarding mobile learning in a population that owns personal mobile devices and claim to be able to use them for learning. Moreover, students valued mobile devices advantages of being easy to find up-to-date information, being motivating for learning and being easy to carry. Nevertheless, students acknowledged difficulties in the use of mobile devices to learn, such as needing an internet connection, its slowness, not being allowed to use mobile devices in schools. and the fact that they give access to distractions.

The EduPARK game achieved an average EVS of 83.8, indicating its high educational value, which is supported by the data collected through the app logging mechanisms, as the groups of students achieved a good performance, overall. Additionally, the app achieved an average SUS of 80.2, which comprises a goodexcellent usability (Bangor, Kortum and Miller, 2009), indicating that it is easy to use and promotes authentic learning in this target-public. Resources that combine this set of innovative features - such as being mobile, designed for outdoor use (namely in urban parks), with contextualized contents, supporting game-based geocaching activities and with AR contents - can be easy to use and may promote learning, both at a cognitive level and at an affective one (such as increased motivation for learning). These features (Radu, 2012; Burden and Maher, 2014; Qian and Clark, 2016; Sung, Chang and Liu, 2016; Akçayır and Akçayır, 2017; Laine, 2018; Martí and Mon, 2018) can be successfully integrated in methodologies to teach, in an authentic way, cross-subjects and contextualized issues to Basic Education students in informal settings, such as urban parks.

One of this study limitations is the level of excitement related with the timing and set where one of the data collection tools, the questionnaires, were applied (just after playing the game and in the park), as it may have hindered students' concentration during the questionnaire filling. Nevertheless, to reduce the impact of this factor, children were supported by the adults, who accompanied each group, to assure they understood the questions and answer options, whenever needed. Teams' constitution may also have influenced the results, as each student's level of participation in the game decreases as the number of team members increases. This factor may have impact on how the activity is perceived by the app players. However, this variation in teams' constitution could not be addressed, particularly with activities with a higher number of participants, as it was related with the human resources available to accompany each group of children in each session.

This paper is a contribution to the literature on mobile game-based AR learning, as it includes empirical evidence regarding the effectiveness of the integration of new technologies in $2^{\text {nd }}$ and $3^{\text {rd }} \mathrm{CBE}$ to promote 
students learning. It also bears the report of an example of excellent cross-subjects educational materials the learning game - that comprises a very useful tool for teachers and students to explore scientific knowledge by accessing appealing information on biological and historical references of a local urban park.

\section{ACKNOWLEDGEMENT}

This work is financed by FEDER - Fundo Europeu de Desenvolvimento Regional funds through the COMPETE 2020 - Operational Programme for Competitiveness and Internationalisation (POCI), and by Portuguese funds through FCT - Fundação para a Ciência e a Tecnologia within the framework of the project POCI-01-0145-FEDER-016542.

\section{REFERENCES}

Akçayır, M. and Akçayır, G. (2017) 'Advantages and challenges associated with augmented reality for education: A systematic review of the literature', Educational Research Review, 20, pp. 1-11. doi: 10.1016/j.edurev.2016.11.002.

Azuma, R. et al. (2001) 'Recent Advances in Augmented Reality', IEEE Computer Graphics and Applications, 21(6), pp. 34-47.

Bacca, J. et al. (2014) 'Augmented Reality Trends in Education: A Systematic Review of Research and Applications', Educational Technology \& Society, 17(4), pp. 133-149. Available at: https://eric.ed.gov/?id=EJ1045535 (Accessed: 7 March 2017).

Ballantyne, R., Packer, J. and Hughes, K. (2008) 'Environmental awareness, interests and motives of botanic gardens visitors: Implications for interpretive practice', Tourism Management, 29(3), pp. 439-444. doi: 10.1016/j.tourman.2007.05.006.

Bangor, A., Kortum, P. and Miller, J. (2009) 'Determining What Individual SUS Scores Mean: Adding an Adjective Rating Scale', Journal of Usability Studies, 4(3), pp. 114-123. Available at: http://www.usabilityprofessionals.org. (Accessed: 10 February 2017).

Barnes, J. (2015) Cross-Curricular Learning 3-14. 3rd edn. London: Sage Publications.

Brooke, J. (1996) 'SUS - A quick and dirty usability scale', in Jordan, P. W. et al. (eds) Usability Evaluation in Industry. London: Taylor \& Francis, pp. 189-194.

Burden, K. and Maher, D. (2014) 'Mobile technologies and authentic learning in the primary school classroom', in Kevin Burden, Marilyn Leask, and Sarah Younie (eds) Teaching With ICT in the Primary School. Routledge, pp. 171-182. Available at: https://core.ac.uk/download/pdf/151161512.pdf (Accessed: 9 October 2018).

Chee, K. N. et al. (2017) 'Review of Mobile Learning Trends 2010-2015: A Meta-Analysis', Educational Technology \& Society, 20(2), pp. 113-126. Available at: http://www.ifets.info/journals/20_2/10.pdf (Accessed: 13 January 2018).

Crompton, H., Burke, D. and Gregory, K. H. (2017) 'The use of mobile learning in PK-12 education: A systematic review', Computers \& Education, 110, pp. 51-63. doi: 10.1016/J.COMPEDU.2017.03.013.

Dunleavy, M. and Dede, C. (2014) 'Augmented Reality Teaching and Learning', in Spector, M. et al. (eds) The Handbook of Research for Educational Communications and Technology. 4th edn. New York: Springer, pp. 735-745. doi: 10.1007/978-1-4614-3185-5.

Giannakas, F. et al. (2018) 'A critical review of 13 years of mobile game-based learning', Educational Technology Research and Development. Springer US, 66(2), pp. 341-384. doi: 10.1007/s11423-017-9552-z. Herrington, J. and Parker, J. (2013) 'Emerging technologies as cognitive tools for authentic learning', British Journal of Educational Technology. Wiley/Blackwell (10.1111), 44(4), pp. 607-615. doi: 10.1111/bjet.12048.

Kenney, E. L. and Gortmaker, S. L. (2017) 'United States Adolescents' Television, Computer, Videogame, Smartphone, and Tablet Use: Associations with Sugary Drinks, Sleep, Physical Activity, and Obesity', The Journal of Pediatrics. Mosby, 182, pp. 144-149. doi: 10.1016/J.JPEDS.2016.11.015. 
Ketelhut, D. J. and Schifter, C. C. (2011) 'Teachers and game-based learning: Improving understanding of how to increase efficacy of adoption', Computers and Education. Elsevier Ltd, 56(2), pp. 539-546. doi: 10.1016/j.compedu.2010.10.002.

Laine, T. (2018) 'Mobile Educational Augmented Reality Games: A Systematic Literature Review and Two Case Studies', Computers, 7(1), p. 19. doi: 10.3390/computers7010019.

Liu, M. et al. (2014) 'A look at research on mobile learning in K-12 education from 2007 to the present', Journal of Research on Technology in Education, 46(4), pp. 325-372. doi: 10.1080/15391523.2014.925681.

Martí, M. C. and Mon, F. M. E. (2018) 'El uso de las tabletas y su impacto en el aprendizaje. Una investigación nacional en centros de Educación Primaria’, Revista de Educación, (379), pp. 170-191. doi: 10.4438/1988-592X-RE-2017-379-366.

Martins, A. I. et al. (2015) 'European Portuguese Validation of the System Usability Scale (SUS)', Procedia Computer Science, 67, pp. 293-300. doi: 10.1016/j.procs.2015.09.273.

Parsons, D. (2014) 'The Future of Mobile Learning and Implications for Education and Training', in Ally, M. and Tsinakos, A. (eds) Increasing Access through Mobile Learning. Vancouver: Commonwealth of Learning and Athabasca University, pp. 217-229.

Pedro, L. F. M. G., Barbosa, C. M. M. de O. and Santos, C. M. das N. (2018) 'A critical review of mobile learning integration in formal educational contexts', International Journal of Educational Technology in Higher Education. doi: 10.1186/s41239-018-0091-4.

Pereira, R., Lopes, L. and Pinho, R. (2006) Património histórico e botânico do Fontelo : um contributo para actividades de educação ambiental em espaços urbanos. Câmara Mun. Viseu.

Plomp, T. and Nieveen, N. (2013) Educational Design Research - Part A: An Introduction, Educational Design Research. Enschede, the Netherlands: SLO - Netherlands institute for curriculum development. doi: 10.1007/978-1-4614-3185-5_11.

Pombo, L. et al. (2011) 'Evaluation of the quality of Science Education programmes that use Web 2.0 tools an Anglo-Portuguese Research Project', Educação, Formação \& Tecnologias - ISSN 1646-933X, n. ${ }^{\circ}$ extra(Abril de 2011), pp. 28-36.

Pombo, L., Marques, M. M., Lucas, M., et al. (2017) 'Moving learning into a smart urban park: Students' perceptions of the Augmented Reality EduPARK mobile game', Interaction Design and Architecture $(s)$ Journal - IxD\&A, (35), pp. 117-134.

Pombo, L., Marques, M. M., Loureiro, M. J., et al. (2017) Parque Infante D. Pedro, Património Histórico e Botânico - Projeto EduPARK. Edited by L. Pombo. Aveiro: UA Editora. Available at: http://edupark.web.ua.pt/static/docs/Livro_EduPARK.pdf.

Pombo, L. et al. (in press) 'Evaluation of an Augmented Reality Mobile Gamelike Application as an Outdoor Learning Tool', International Journal of Mobile and Blended Learning (IJMBL).

Pombo, L., Loureiro, M. J. and Moreira, A. (2010) 'Assessing collaborative work in a higher education blended learning context: strategies and students' perceptions', Educational Media International, 47(3), pp. 217-229. doi: 10.1080/09523987.2010.518814.

Pombo, L., Loureiro, M. J. and Moreira, A. (2011) 'Guidelines for Effective bLearning in Teacher Education: Experience Gathered from the Three Cycles of Higher Education’, in Bhattacharya, M., Mach, N., and Moallem, M. (eds) Emerging Technologies in Learning: Impact on Cognition and Culture. Association for the Advancement of Computing in Education (AACE)., pp. 259-268. Available at: https://www.learntechlib.org/noaccess/39252/\#page=260 (Accessed: 19 June 2019).

Pombo, L. and Marques, M. M. (2017) 'Marker-based augmented reality application for mobile learning in an urban park - Steps to make it real under the EduPARK project', in Ponte, C., Dodero, J. M., and Silva, M. J. (eds) XIX International Symposium on Computers in Education (SIIE) and VIII CIED Meeting/ III CIED International Meeting. Lisbon: Polytechnic Institute of Lisbon, School of Education, pp. 174-178. Available at: http://edupark.web.ua.pt/static/docs/EduPARK-SIIE2017.pdf.

Pombo, L. and Marques, M. M. (2018) 'The EduPARK mobile augmented reality game: Learning value and usabiliy', in Sánchez, I. A. and Isaias, P. (eds) 14th International Conference Mobile Learning 2018. Lisbon: IADIS, pp. 23-30.

Pombo, L. and Marques, M. M. (in press) 'Learning with the augmented reality EduPARK game-like app: its usability and educational value for primary education', in Computing Conference, 16-17 July. London. 
Qian, M. and Clark, K. R. (2016) 'Game-based Learning and 21st century skills: A review of recent research', Computers in Human Behavior, 63, pp. 50-58. doi: 10.1016/j.chb.2016.05.023.

Radu, I. (2012) 'Why should my students use AR? A comparative review of the educational impacts of augmented-reality’, in 2012 IEEE International Symposium on Mixed and Augmented Reality (ISMAR). IEEE, pp. 313-314. doi: 10.1109/ISMAR.2012.6402590.

Reyes, M. R. et al. (2012) 'Classroom Emotional Climate, Student Engagement, and Academic Achievement', Journal of Educational Psychology, 104(3), pp. 700-712. doi: 10.1037/a0027268.

Sauro, J. (2011) MeasuringU: Measuring Usability with the System Usability Scale (SUS), MeasuringU. Available at: http://measuringu.com/sus/ (Accessed: 10 February 2017).

Simões, J. A. et al. (2014) Crianças e Meios Digitais Móveis em Portugal: Resultados Nacionais do Projeto Net Children Go Mobile. Lisboa. Available at: http://netchildrengomobile.eu/ncgm/wpcontent/uploads/2013/07/ncgm_pt_relatorio1.pdf.

Sung, Y.-T., Chang, K.-E. and Liu, T.-C. (2016) 'The effects of integrating mobile devices with teaching and learning on students' learning performance: A meta-analysis and research synthesis', Computers \& Education. Pergamon, 94, pp. 252-275. doi: 10.1016/J.COMPEDU.2015.11.008.

Swan, K. et al. (2005) 'Uses and effects of mobile computing devices in k-8 classrooms', Journal of Research on Technology in Education, 38(1), pp. 99-112. doi: 10.1080/15391523.2005.10782451.

Unity Technologies (2017) Unity. Available at: https://unity3d.com/unity (Accessed: 14 February 2017). 